\title{
Substrate Cleaning Processes and Their Influence on the Laser Resistance of Anti-Reflective Coatings
}

\author{
Thomas Gischkat ${ }^{1, *}$, Daniel Schachtler ${ }^{1}$, Igor Stevanovic ${ }^{1,2}$, Zoltan Balogh-Michels ${ }^{1}(\mathbb{D}$, \\ Roelene Botha ${ }^{1,3}$, Andreas Bächli ${ }^{1}{ }^{\circledR}$, Marco Cucinelli ${ }^{3}$, André Mocker ${ }^{3}$, Martin Gutsche ${ }^{3}$, \\ Sven Günther ${ }^{2,4}$, Philipp Alder ${ }^{4}$ and Bernd Eiermann ${ }^{2}$ \\ 1 RhySearch, The Rhine Valley Research and Innovation Center, Werdenbergstrasse 4, 9471 Buchs, Switzerland; \\ daniel.schachtler@rhysearch.ch (D.S.); igor.stevanovic@wzw.ch (I.S.); zoltan.balogh@rhysearch.ch (Z.B.-M.); \\ roelene.botha@rhysearch.ch (R.B.); andreas.baechli@rhysearch.ch (A.B.) \\ 2 WZW Optic AG, Wegenstrasse 18, 9436 Balgach, Switzerland; sven.guenther@wzw.ch (S.G.); \\ bernd.eiermann@wzw.ch (B.E.) \\ 3 Institute of Micro Technology and Photonics (IMP), OST-Eastern Switzerland University of Applied \\ Sciences, Werdenbergstrasse 4, 9471 Buchs, Switzerland; marco.cucinelli@ost.ch (M.C.); \\ andre.mocker@ost.ch (A.M.); martin.gutsche@ost.ch (M.G.) \\ 4 UCM AG, Langenhagstrasse 25, 9424 Rheineck, Switzerland; p.alder@ucm-ag.com \\ * Correspondence: thomas.gischkat@rhysearch.ch; Tel.: +41-(0)81-755-4956
}

Received: 12 November 2020; Accepted: 24 November 2020; Published: 27 November 2020

check for updates

\begin{abstract}
Substrate cleaning prior to coating has a strong influence on the performance of the optical component. Exemplary, none or inadequate cleaning reduces the resistance against laser irradiation drastically. Especially in laser components coated with anti-reflective layers, the interface between substrate and coating is one of the most limiting factors. This study investigates different precision cleaning processes and their influence on the laser resistance of ion-beam sputtered anti-reflective coatings. Therefore, a $\mathrm{SiO}_{2} / \mathrm{Ta}_{2} \mathrm{O}_{5}$ multilayer anti-reflective coating for a wavelength of $1064 \mathrm{~nm}$ and a normal angle of incidence was deposited onto high-quality fused silica substrates. Prior to deposition, the substrates were cleaned with various cleaning processes using different solutions and ultrasonic frequencies. To characterize the cleaned surface quality, the surfaces were analyzed with respect to root-mean-square (RMS) roughness and particle density. Laser damage was measured using a $1064 \mathrm{~nm}$ ns-pulsed laser test bench. It was found that an alcoholic pre-clean is recommendable to prevent laser damage caused by organic films remaining from the polishing process. The applied ultrasonic frequencies strongly influenced the particle density down to the sub-micrometer range and in consequence, the laser-induced damage threshold (LIDT). Ultrasonic cleaning at excessive power levels can reduce laser resistance.
\end{abstract}

Keywords: ultrasonic cleaning; laser-induced damage; LIDT; anti-reflective coating; fused silica; $\mathrm{SiO}_{2} ; \mathrm{Ta}_{2} \mathrm{O}_{5}$

\section{Introduction}

Polishing optical substrates produces numerous different surface contaminants that remain on the surface after process completion [1-4]. The contaminants include particles originating from the polishing abrasive and removed substrate material and organic films from optical paint and cement. The remaining residuals negatively affect the properties and performance of the optical component and can even cause total failure. For example, particles and organic films lead to increased scattering and absorption and can reduce the thin film layer stack's adhesion. Especially in the case of laser components, surfaces with extremely low particle densities must be achieved. In particular, 
the initiation of laser-induced damages can be addressed to absorbing nanometer-sized particles referred to as "nano precursors" [5].

In consequence, particles down to the nanometer-size must be reduced to a minimum. Any remaining organic films negatively influence the laser damage threshold [6,7]. Therefore, appropriate cleaning of the optical substrates is a must for further processing, e.g., coating, assembling [8-14]. However, increasing demands and tight specifications for optical coatings require well understood, clearly defined, and stable cleaning procedures.

For research purposes and in the scientific environment, time-consuming and expensive techniques such as short-time etching in hydrofluoric acid (referred to as HF dip) [15] or spin cleaning can be used. It is worth mentioning that for an HF dip, a rinsing and drying step is necessary, which is critical regarding back-contamination with particles. In case of expensive components, single-part processes like spin cleaning and manual cleaning are also applied in industrial environments. However, usually automatic batch processes for cost reduction and process optimization are preferred. Such processes are ideally well defined and controlled compared to "daily-performance depending" manual processes. Therefore, the most valuable cleaning method is by means of a fully automatic ultrasonic cleaning bench. Surprisingly, detailed investigations on the influence of different process parameters during the ultrasonic cleaning on the cleaning results (e.g., residual particles) are rare. This is partially due to confidential, proprietary issues. Especially for anti-reflective (AR) coatings for laser optics in the nanosecond pulse regime, the laser-induced damage threshold depends strongly on the substrate surface quality prior to coating $[8,10]$. To achieve optimal cleaning results, one has to take the substrate material, the polishing quality, and residuals from the polishing process itself (e.g., polishing material, cement, protective layer) into account when choosing a suitable cleaning procedure. Regarding the substrate material, essential properties are climatic resistance, stain resistance, acid resistance as well as alkaline and phosphate resistance, Knoop hardness, and the thermal expansion coefficient. It also has to be mentioned that permeate and deionized water act as acids due to their chemical behavior. Inadequate cleaning can subsequently attack the substrate surface. Consequently, the roughness can increase dramatically, and the chemical composition of the surface can change. Standard automatic cleaning processes consist of the following elements:

1. Various cleaning steps make use of acids or alkaline solutions, depending on the glass material used, to remove polishing residuals or fingerprints from handling.

2. By increasing the ultrasonic frequency in the subsequent steps, particles with ever-decreasing dimensions can be removed.

3. Between successive cleaning steps, the chemical solution has to be removed quickly from the substrate surface using permeate as well as deionized water.

4. Drying of the substrates is crucial and can be done by infrared radiation, hot airflow, or an alcoholic vapor.

To remove unknown organic films from the surface, a pre-cleaning step based on organic solutions such as acetone or, due to safety issues in the industry, by modified alcohol (AIII) can be performed. After cleaning, the surfaces are typically inspected in transmission using a spot lamp or a dark-field microscope. Unfortunately, in most cases, particles with dimensions in the sub-micron and nanometer regime are not detected and can remain unidentified on the surface.

In this work, we present a study on the influence of a variety of cleaning processes on the surface quality as well as on the laser-induced damage threshold (LIDT) at $1064 \mathrm{~nm}$ (ns-laser) of AR-coated samples. The chosen cleaning experiments include variations in applied ultrasonic frequency and tests with and without alcoholic pre-clean.

\section{Materials and Methods}

As substrates for the cleaning experiments, we used fused silica samples with a diameter of $25 \mathrm{~mm}$ and a thickness of $2 \mathrm{~mm}$ provided by WZW Optic AG. Fused silica was selected because of its 
high quality, high LIDT, and high chemical resistance to avoid any influence of the substrate material itself. The samples were P4-polished on both sides with an RMS roughness of about $3 \AA$. The specified surface quality (scratch-dig), according to MIL-PRF-13830B, was 10-5.

\subsection{Sample Preparation}

\subsubsection{Cleaning Prior to Coating}

Two different sets of cleaning processes were applied. Samples of set A were cleaned using a standard semiconductor wet bench equipped with a quick dump rinse. The change of cleaning baths was done manually. A fully automatic cleaning was performed for samples of set B using an industrial ultrasonic cleaning machine provided by UCM AG. According to a specified recipe, the substrates dwell for a well-defined time in the baths and were transported entirely automatically from bath to bath. A total of seven different water-based precision cleaning processes referred to as A-CP1, A-CP2, A-CP3 for set A and B-CP1, B-CP2, B-CP3, B-CP4 for set B, respectively, were applied on the uncoated samples prior to coating. For better comparison, the referenced standard cleaning process was A-CP1.

In all cases, the precision cleaning steps were: cleaning 1-rinsing-cleaning 2-rinsing-rinsinglift-out-drying. As water-based chemicals for cleaning 1 and cleaning 2 deconex ${ }^{\circledR}$ OP 148 (3 vol\%, $\mathrm{pH}$ value of 12) and deconex ${ }^{\circledR}$ OP 164 (2 vol\%, pH value of 7) from Borer-Chemie AG were used, respectively. In case of set $\mathrm{A}$, the samples were dried in an oven under air for $600 \mathrm{~s}$ at a temperature of $75^{\circ} \mathrm{C}$. To avoid renewed contamination with particles, the oven was equipped with a HEPA-filter. In case of set $\mathrm{B}$, the samples were dried with infrared heaters. To investigate the influence of ultrasonic frequencies and power, we used ultrasonic of about 40, 80, 120 as well $500 \mathrm{kHz}$ (A-CP3, B-CP2-B-CP4), whereas in case of A-CP3 the ultrasonic power was not adjusted. Prior to precisions cleaning, some substrates were pre-cleaned using solvents. As the solvent, acetone at room temperature without ultrasonic assistance was used. As acetone is highly volatile, purging by means of isopropanol (IPA) after the acetone bath is recommended. In Table 1, the parameters of the cleaning processes are summarized.

Table 1. Applied ultrasonic frequencies and process times for the ultrasonic cleaning steps as well as the fine-rinsing step used for cleaning processes of set $A$ and set $B$.

\begin{tabular}{|c|c|c|c|c|c|}
\hline \multicolumn{2}{|c|}{ Cleaning Process } & \multirow{2}{*}{$\frac{\text { Pre-Clean }}{\text { Yes }}$} & \multirow{2}{*}{ 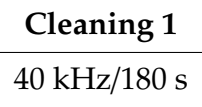 } & \multirow{2}{*}{$\frac{\text { Cleaning } 2}{40 \mathrm{kHz} / 180 \mathrm{~s}}$} & \multirow{2}{*}{$\frac{\text { Rinsing }}{-/ 2 \times 180 \mathrm{~s}}$} \\
\hline Set A & A-CP1 & & & & \\
\hline & $\mathrm{A}-\mathrm{CP} 2$ & No & $40 \mathrm{kHz} / 180 \mathrm{~s}$ & $40 \mathrm{kHz} / 180 \mathrm{~s}$ & $-/ 2 \times 180 \mathrm{~s}$ \\
\hline & $\mathrm{A}-\mathrm{CP} 3$ & Yes & $40 \mathrm{kHz} / 180 \mathrm{~s}$ & $\begin{array}{c}40 \mathrm{kHz}^{1} / 60 \mathrm{~s} \\
80 \mathrm{kHz}^{1} / 60 \mathrm{~s} \\
120 \mathrm{kHz}^{1} / 60 \mathrm{~s}\end{array}$ & $-/ 2 \times 180 s$ \\
\hline \multirow[t]{4}{*}{ Set B } & $\mathrm{B}-\mathrm{CP} 1$ & Yes & $40 \mathrm{kHz} / 180 \mathrm{~s}$ & $40 \mathrm{kHz} / 180 \mathrm{~s}$ & $-/ 2 \times 180 \mathrm{~s}$ \\
\hline & $\mathrm{B}-\mathrm{CP} 2$ & Yes & $40 \mathrm{kHz} / 180 \mathrm{~s}$ & $\begin{array}{c}40 \mathrm{kHz} / 60 \mathrm{~s} \\
80 \mathrm{kHz} / 60 \mathrm{~s} \\
120 \mathrm{kHz} / 60 \mathrm{~s}\end{array}$ & $-/ 2 \times 180 \mathrm{~s}$ \\
\hline & $\mathrm{B}-\mathrm{CP} 3$ & Yes & $40 \mathrm{kHz} / 300 \mathrm{~s}$ & $\begin{array}{c}80 \mathrm{kHz} / 150 \mathrm{~s} \\
120 \mathrm{kHz} / 150 \mathrm{~s}\end{array}$ & $-/ 2 \times 180 \mathrm{~s}$ \\
\hline & $\mathrm{B}-\mathrm{CP} 4$ & Yes & $40 \mathrm{kHz} / 180 \mathrm{~s}$ & $\begin{array}{c}40 \mathrm{kHz} / 60 \mathrm{~s} \\
80 \mathrm{kHz} / 60 \mathrm{~s} \\
120 \mathrm{kHz} / 60 \mathrm{~s}\end{array}$ & $500 \mathrm{kHz} / 2 \times 180 \mathrm{~s}$ \\
\hline
\end{tabular}

\footnotetext{
${ }^{1}$ No ultrasonic power adjustment.
} 


\subsubsection{Anti-Reflective Coating}

After the precision cleaning, an anti-reflective coating was deposited onto the substrates by means of ion beam sputtering using a Veeco Spector 1.5 system located in a cleanroom environment (ISO 5-7). As layer materials, $\mathrm{SiO}_{2}(n=1.482 @ 1064 \mathrm{~nm})$ and $\mathrm{Ta}_{2} \mathrm{O}_{5}(n=2.087 @ 1064 \mathrm{~nm})$ were used. The multi-layer AR coating was designed for $1064 \mathrm{~nm}$ and normal incidence (angle of incidence $\left.\mathrm{AOI}=0^{\circ}\right)$ starting with a $2 \mathrm{QWT}-1$ layer $\mathrm{SiO}_{2}(\mathrm{sub} / 2 \mathrm{~L} 0.64 \mathrm{H} 0.44 \mathrm{~L} 0.23 \mathrm{H} 0.59 \mathrm{~L} / \mathrm{air})$. Before coating, the coating chamber was pre-heated to $105^{\circ} \mathrm{C}$, and the temperature was kept constant during the thin film deposition. To avoid any influence of layer thickness distribution in the coating chamber, the substrates were placed at equal positions in the substrate holder. Figure 1 shows the AR-coated test sample's measured reflectivity with $\mathrm{R}<0.1 \%$ at $1064 \mathrm{~nm}$.

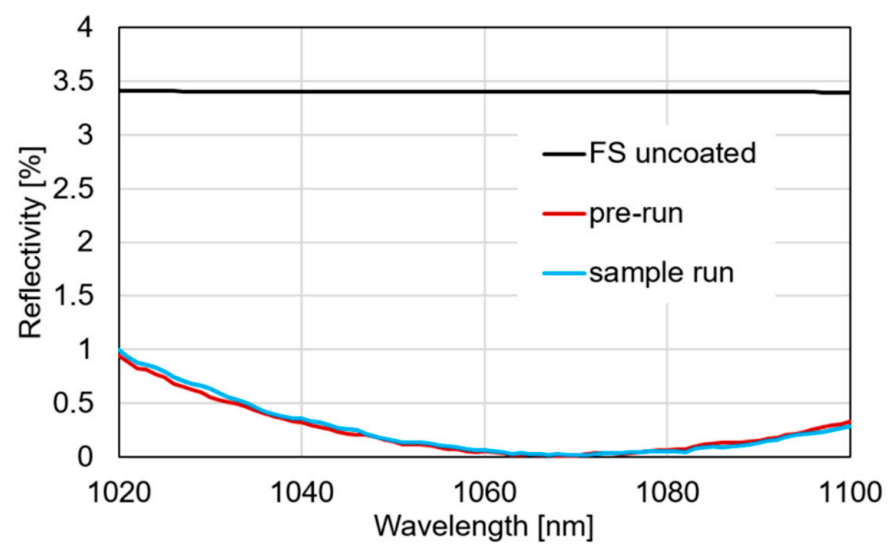

Figure 1. Measured reflectivity of the AR-coated fused silica test sample $\left(\mathrm{AOI}=7^{\circ}\right)$.

\subsection{Sample Characterization}

\subsubsection{Surface Inspection}

After cleaning, the samples were inspected in transmission and reflection by means of a spot lamp. A modified inspection microscope Leica type INM200 was used for a more precise and sensitive inspection of the cleaned surfaces. The microscope is equipped with an automated objective revolver (magnifications: $2.5 \times, 5 \times, 10 \times, 20 \times, 50 \times, 100 \times$ ) and an Ul-3060CP-C-HQ camera with a $2.3 \mathrm{MP}$ Sony sensor $(1936 \times 1216 \mathrm{px}, 166 \mathrm{fps})$. The modified system can detect particles greater than $83 \mathrm{~nm}$ by using the objective with the highest magnification of about $100 \times$ and using bright field illumination. To avoid particle contamination during handling and measurement, the whole system is installed in an ISO 1 housing. The whole surface except $2 \mathrm{~mm}$ edge exclusion was scanned automatically. The detected particles were assigned in a histogram with defined particle size classes (83-100 nm; 100-200 nm; 200-300 nm; 300-500 nm; 500-1000 nm; 1000-5000 nm and greater than $5000 \mathrm{~nm}$ ).

In addition, the root-mean-square roughness was measured by means of a white light interferometer Zygo NewView 5300 to detect changes in the surface roughness.

\subsubsection{Laser Damage Testing}

The laser-induced damage threshold (LIDT) measurement was performed at the laser damage test bench located at the RhySearch optical coating laboratory. Herewith the cleaned bare substrates and the subsequently coated AR samples were laser damage tested. The laser irradiation at $1064 \mathrm{~nm}$ was performed using a diode-pumped Nd:YAG laser system. The effective pulse duration was about $10 \mathrm{~ns}$, and the repetition rate was $100 \mathrm{~Hz}$. In accordance with ISO norm 21,254, the Gaussian beam profile's effective beam diameter was above $200 \mu \mathrm{m}$ (1/e2). An S-on-1 measurement strategy [15] was applied whereby $S=5000$. The centered test area was $20 \mathrm{~mm}$ in diameter and divided into a test matrix. According to the beam diameter and the ISO norm, each test site's distances were larger than 5 times 
the beam diameter. A set of three samples per cleaning process were laser damage tested under an angle of incidence of $5^{\circ}$. The measurement was performed in filtered air and at room temperature. The detection of damage events was done by a scattering detector that was placed in front of the test sample. To verify the detected damage events, visual inspection by means of differential interference contrast DIC-microscopy was performed.

\section{Results}

\subsection{Surface Quality}

In Figure 2, the number of particles counted on the samples cleaned with A-CP1 to B-CP4 is a logarithmic scale. The highest particle count occurred for standard automatic cleaning using only $40 \mathrm{kHz}$ ultrasonic (B-CP1). For example, a dramatically high number of about 227 particles with a size between 1 and $5 \mu \mathrm{m}$ were counted and even 576 particles were detected with a size between 100 and $200 \mathrm{~nm}$. Applied additional 80 and $120 \mathrm{kHz}$ (B-CP2) instead of only $40 \mathrm{kHz}$ brings down the particle count to 48 and 109 for particle classes 1 to $5 \mu \mathrm{m}$ and 100 to $200 \mathrm{~nm}$, respectively. In both cases, particles greater than $5 \mu \mathrm{m}$ were detected with an amount of 6 and 4, respectively. For high-end optical applications, these numbers are still unacceptably high. A drastic reduction in remaining particles down to roughly 10 particles on the surface is obtained for longer dwell time (B-CP3), an additional application of $500 \mathrm{kHz}$ ultrasonic during standard rinsing (B-CP4), or quick dump rinse (A-CP1). In these cases, no particles greater than $5 \mu \mathrm{m}$ were detected. In all cases, no prediction can be made on particles smaller than $83 \mathrm{~nm}$, but it is intuitively clear that such particles exist.

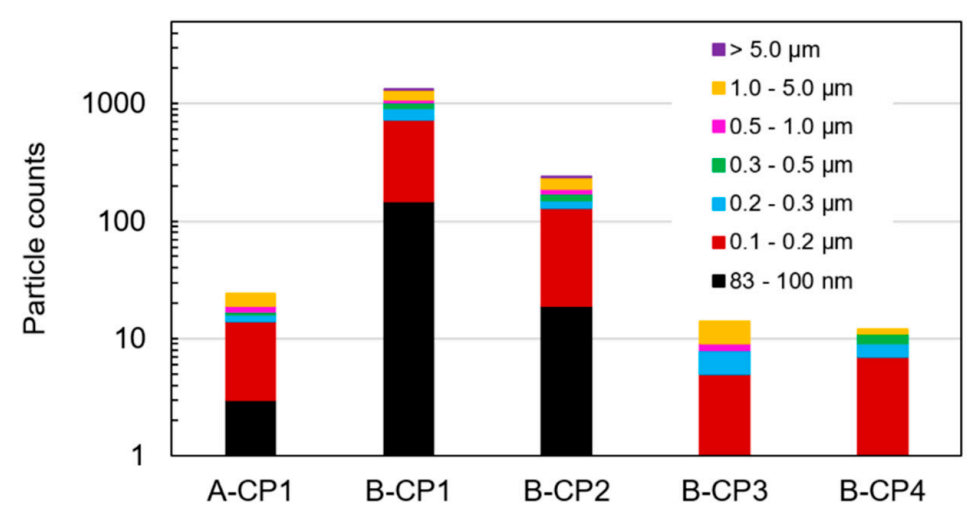

Figure 2. Particle counts for cleaning processes A-CP1 to B-CP4 in a logarithmic scale.

Whereas the particle density strongly depends on the applied cleaning strategy, the RMS surface roughness seems to be independent of the cleaning process. Figure 3 shows the white light interferometer scans (scan size: $0.53 \mathrm{~mm} \times 0.71 \mathrm{~mm}$ ) of the surface prior to cleaning and after cleaning (B-CP1) as well as after coating (B-CP2). As can be seen, the as-polished sample's surface provides a high quality and random polishing structure with an RMS roughness of about $2.3 \AA$. No scratches or polishing traces are visible in the interferogram. The mean value of the RMS roughness of the as-polished samples is $2.7 \AA$. After cleaning and coating, the random structure and RMS roughness remain almost unchanged with $3.2 \AA$. Table 2 shows the RMS roughness measurements for the cleaning of set A and set B. 


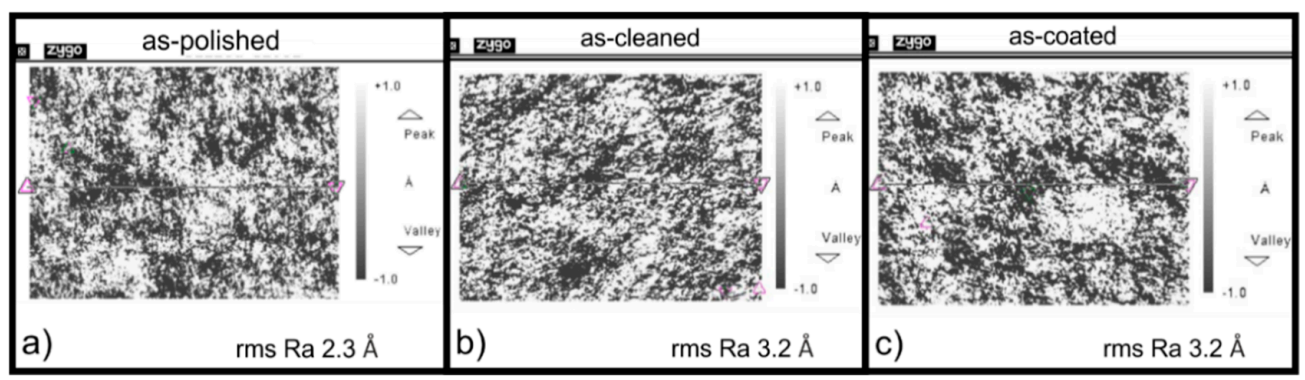

Figure 3. Plot of the white light interferometer measurements of (a) a polished sample, (b) a cleaned sample $(\mathrm{CP} 1$; RMS roughness $=3.2 \AA)$, and $(\mathrm{c})$ a coated sample $(\mathrm{CP} 2$; RMS roughness $=3.2 \AA$ ).

Table 2. Root-mean-square (RMS) roughness of the as-polished, as-cleaned, and as-coated samples measured by means of a white light interferometer at WZW Optic AG.

\begin{tabular}{ccccc}
\hline & As-Polished & \multicolumn{2}{c}{ As-Cleaned } & As-Coated \\
\hline & & Set A & Set B & Set A \\
RMS roughness $[\AA]$ & $2.7+/-0.5$ & $3.2+/-0.1$ & $2.7+/-0.5$ & $3.1+/-0.3$ \\
\hline
\end{tabular}

\subsection{Laser-Induced Damage Threshold}

To investigate the influence of the applied cleaning strategy on the LIDT of the as-cleaned substrates, a set of samples without an AR coating were laser damage tested at $1064 \mathrm{~nm}$ with $10 \mathrm{~ns}$ pulses subsequent to the cleaning. Due to the high surface quality, the estimated $0 \%$ LIDT values were between 95 and $230 \mathrm{~J} / \mathrm{cm}^{2}$, which is in the range of the bulk LIDT. We assume that the observed damage is not limited to the surface. Figure 4 shows a picture of an uncoated sample after laser damage testing. Due to the high fluences, the damage events produce large cracks and many particles that affect the subsequent measuring sites. Therefore, no analyzable damage probability curve, and no clear correlation between cleaning and LIDT were observed.

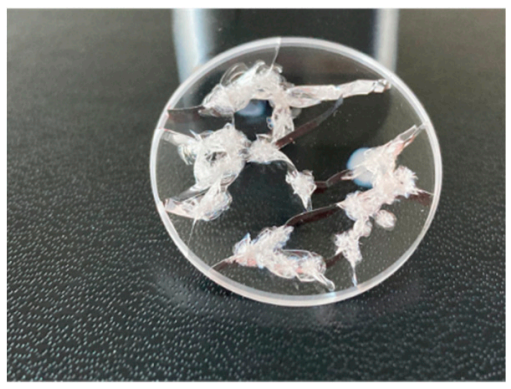

Figure 4. Typical picture of an as-cleaned uncoated sample after laser damage testing.

Subsequent to coating, the simultaneously AR-coated samples were laser irradiated using the same parameters (1064 nm, $10 \mathrm{~ns}$ pulses). Figure 5 shows exemplary results of the laser damage testing. From the data points (black crosses) in Figure $5 \mathrm{a}$, the damage probabilities (blue dots) were calculated using the cumulative data reduction technique [16]. In accordance with ISO 21254, a linear fit was applied (dashed line). The corresponding characteristic damage curve is shown in Figure $5 \mathrm{~b}$. As can be seen, the LIDT saturates between 100 and 1000 pulses. Furthermore, no significant mitigation effects were observed. 

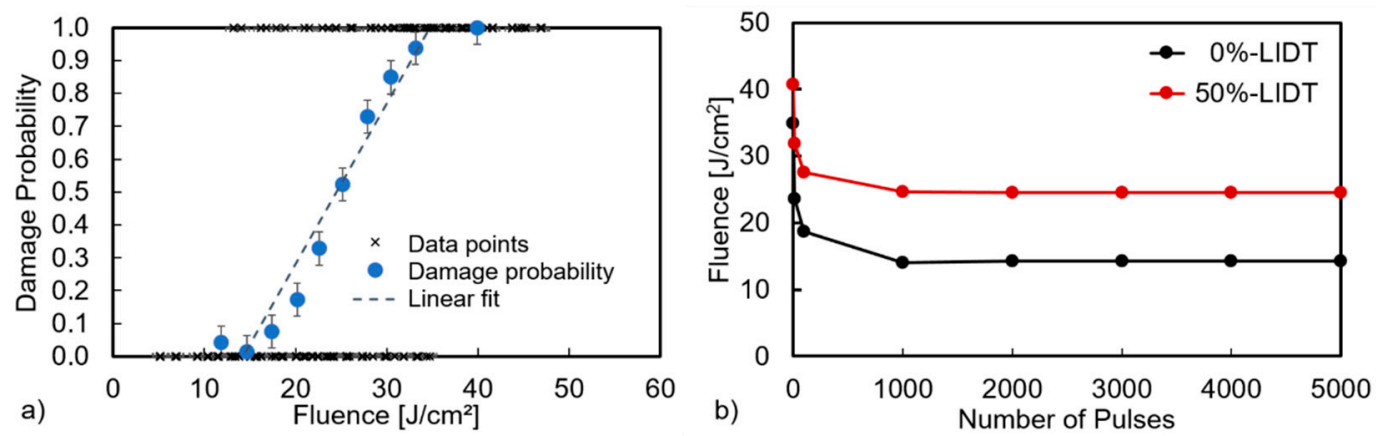

Figure 5. Laser damage testing results of the sample cleaned using process A-CP1: (a) damage probability curve and (b) characteristic damage curve for the $0 \%$ and $50 \%$ laser-induced damage threshold (LIDT) as a function of the number of pulses.

Taking this into account when calculating the $0 \%$ and $50 \%$ LIDT values, the results after 100 pulses were used and depicted for the different sets of cleaning processes in Figure 6. For better comparison, the LIDT values were normalized to the LIDT of the standard cleaning process A-CP1 in Figure 6a,b. The results from set A indicated that the standard process, including an alcoholic pre-clean, gave the best LIDT results. Without pre-clean (A-CP2), the LIDT was reduced by about 35\%. In case of ultrasonic frequency variation without power adjustment in A-CP3 the LIDT was reduced by almost $50 \%$ compared to the standard cleaning. In contrast, applying the automatic cleaning procedure combined with the same variation of the ultrasonic frequencies but with power adjustment in bath 2 (B-CP2) increased approximately 20\% compared to cleaning B-CP1 using only $40 \mathrm{kHz}$. The reduced LIDT values observed for B-CP3 indicated that an adequate composition of ultrasonic frequencies must be chosen. The best results for LIDT and automatic cleaning were observed with an additional $500 \mathrm{kHz}$ step (B-CP4), similar to the standard manual cleaning A-CP1.
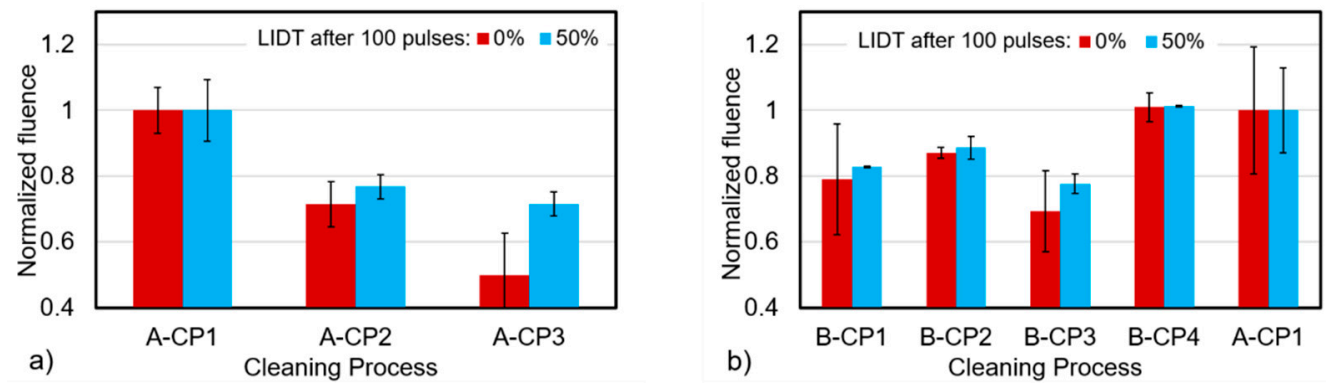

Figure 6. The $0 \%$ and $50 \%$ LIDT for (a) cleaning process set A and (b) cleaning process set $\mathrm{B}$. The estimated fluences are normalized to the values of the standard cleaning A-CP1.

\section{Discussion}

It was shown in Section 3 that the particular choice of cleaning process has a strong influence on the density of the detectable particles remaining after cleaning and the LIDT of subsequently AR-coated samples. Though a low particle density does not guarantee higher LIDT values:

(1) It is well known that non-appropriate ultrasonic frequency and power during precision cleaning can negatively influence the substrate surface's quality. The worst case is a degradation of the surface quality. Hence, the laser damage resistance also decreases significantly. Figure 7 shows microscopic pictures of typical damage morphologies for the samples cleaned with different ultrasonic frequencies and power. In the sample cleaned prior to coating with A-CP3 (Figure 7a), we assume a slight but hardly detectable change in the surface quality (sub-surface damaged layer), leading to the $50 \%$ decreased LIDT compared to the standard cleaning of A-CP1 with adjusted ultrasonic power. This is confirmed by comparing the damage morphologies for samples cleaned with adjusted ultrasonic power (Figure $7 \mathrm{~b}, \mathrm{c}$ ). 
(2) With the help of alcoholic solutions applied prior to the precision cleaning step, many organic compounds can be removed from the substrate surface. Figure 8 shows the comparison of the damage morphology between samples that were pre-cleaned with an alcoholic solution (Figure 8a) and samples that were not pre-cleaned (Figure $8 \mathrm{~b}$ ). The difference in the damage morphology and the appearance clearly shows the influence of the organic residuals. These organic surface residuals bring a decrease in the LIDT of about $35 \%$.

(3) Using the inspection microscope Leica type INM200, only particles with a size above $83 \mathrm{~nm}$ were detected. Potential smaller particles were not detected. In the case of B-CP3 and B-CP4, the total number of particles was 14 and 12, respectively. The particle size distribution also shows no significant difference. However, for B-CP3, the LIDT is roughly $30 \%$ lower compared to B-CP4. A cross-comparison can lead to the assumption that particles smaller than $83 \mathrm{~nm}$ remain undetected on the cleaned surface prior to coating. It is known that the adhesion force of particles increases with decreasing particle size [17]. Furthermore, increasing ultrasonic frequencies up to megasonics increased the efficiency of removing particles with decreasing size down to nanoparticles. Hence, we assume that these particles' cleaning efficiency is higher for B-CP4 and the applied $500 \mathrm{kHz}$ during fine rinsing compared to B-CP3 without ultrasonic assistance during fine rinsing. This is confirmed by comparing the LIDT results of $\mathrm{B}-\mathrm{CP} 4$ with A-CP1, which was equipped with a quick dump rinse (QDR). The QDR technology is well known to reduce back contamination with chemicals and particles from the cleaning solution due to an efficient and fast removal step (few seconds) in which the water is in a quasi "free fall" [18].
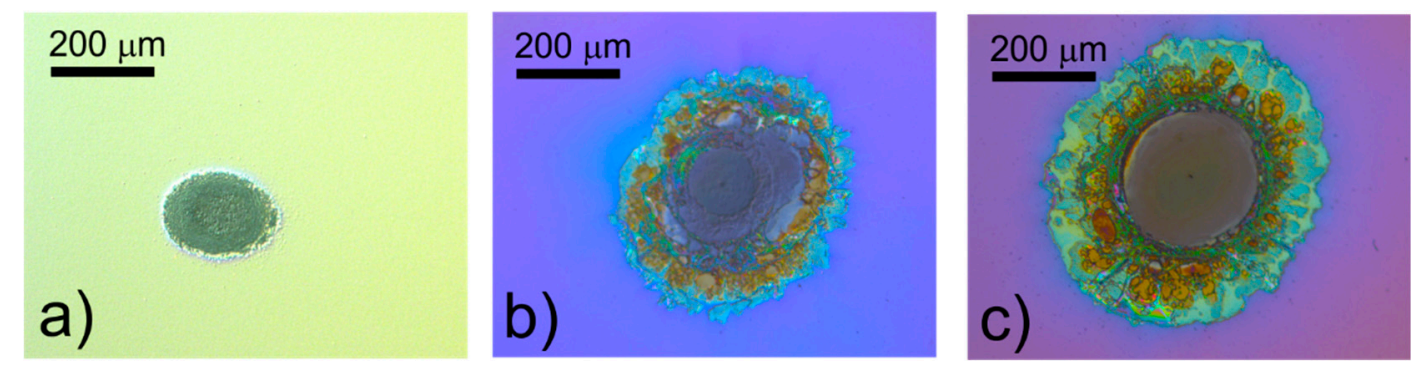

Figure 7. Typical microscopic pictures of damage sites of (a) a sample cleaned without adjusting the power of 80 and $120 \mathrm{kHz}\left(\mathrm{A}-\mathrm{CP} 3,7 \mathrm{~J} / \mathrm{cm}^{2}\right)$, (b) a sample cleaned using only $40 \mathrm{kHz}\left(\mathrm{B}-\mathrm{CP} 1,52 \mathrm{~J} / \mathrm{cm}^{2}\right.$ ) and for comparison (c) a sample with adjusted power at 80 and $120 \mathrm{kHz}$ and additional $500 \mathrm{kHz}$ during fine rinsing (B-CP4, $\left.70 \mathrm{~J} / \mathrm{cm}^{2}\right)$.
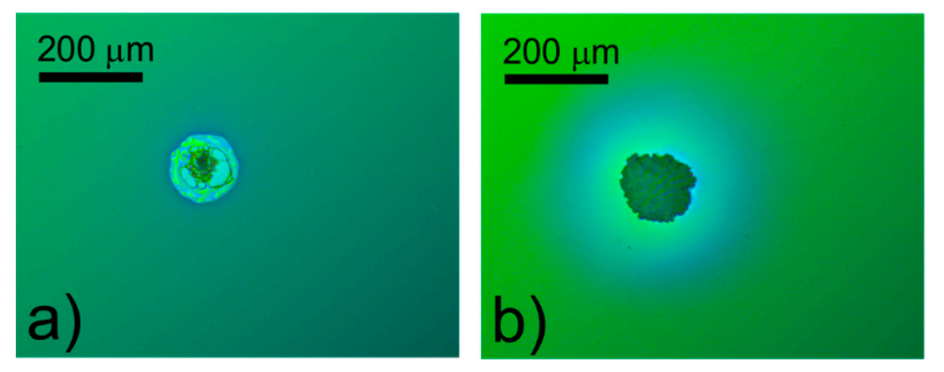

Figure 8. Typical microscopic pictures of damage sites of (a) a sample pre-cleaned with an alcoholic solution $\left(A-C P 1,20 \mathrm{~J} / \mathrm{cm}^{2}\right)$ and $(\mathbf{b})$ a sample that was not pre-cleaned $\left(\mathrm{A}-\mathrm{CP} 2,13 \mathrm{~J} / \mathrm{cm}^{2}\right)$.

Under consideration of surface effects (polishing quality, organic residuals), Figure 9 summarizes the normalized LIDT (see Figure 6) as a function of the total particle count after cleaning, excluding results from A-CP2 and A-CP3. Considering that the LIDT in case of B-CP3 (indicated by the red circle in Figure 9) is influenced by particles smaller than $83 \mathrm{~nm}$, a correlation between LIDT and particle density exists. The same tendency was observed for each single particle class (not shown in detail). The highest detected particle density leads to the lowest LIDT values. With decreasing particle density, the LIDT values increase by about $20 \%$. 


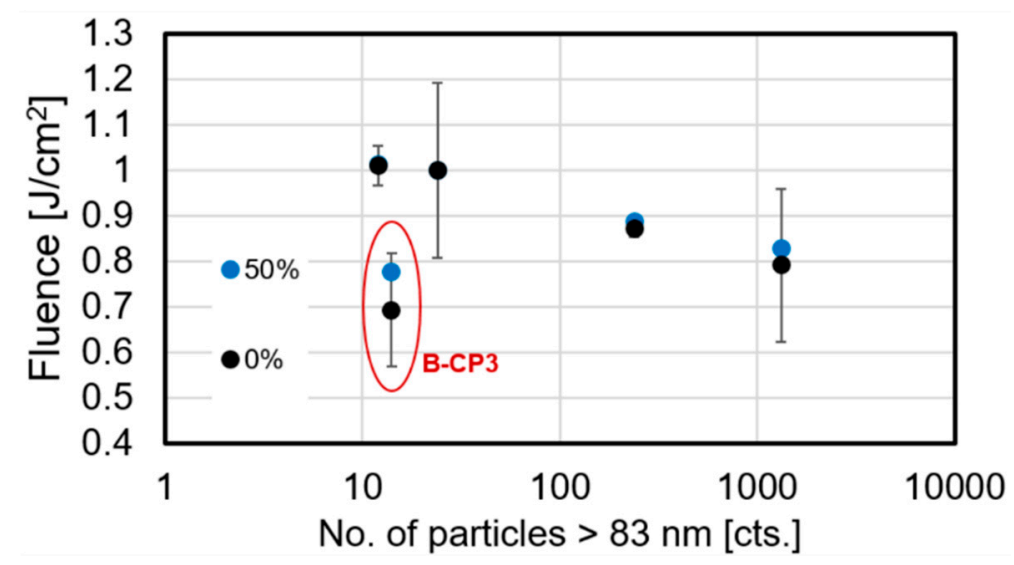

Figure 9. Normalized fluence of the $0 \%$ and $50 \%$ LIDT from Figure $6 \mathrm{~b}$ as a function of measured (total) number of particles.

\section{Conclusions}

Cleaning of substrates prior to coating is crucial to achieving the best performance of optical components. The paper reports on a study of the impact of the type of ultrasonic cleaning prior to coating on the density of particles remaining on the surface as well as on the laser-induced damage behavior of AR-coated substrates for $1064 \mathrm{~nm}$ and $10 \mathrm{~ns}$ pulses. Different applied ultrasonic frequencies and processes lead to different numbers of remaining (detectable) particles (size $>83 \mathrm{~nm}$ ). The particle counts were between 12 and 1320. The lowest particle density was observed for longer process time(s), an additional $500 \mathrm{kHz}$ step applied during fine rinsing, and wet bench cleaning using a quick dump rinse.

It can be concluded that the cleaning process and in consequence the number of counted particles has a direct influence on the laser-induced damage threshold. The higher the particle density, the lower the LIDT. However, besides particles, additional surface effects lower the laser damage resistance: (1) surface polish quality, (2) organic residuals and particles $<83 \mathrm{~nm}$. For the highest LIDT values of coated optics, all these factors must be reduced to a minimum. Therefore, further investigations will be performed on the influence of cleaning parameters on the surface quality and, in consequence, on the laser damage resistance.

Author Contributions: Investigation, T.G., D.S., I.S., Z.B.-M., R.B., M.C., A.M., S.G., B.E.; writing—original draft preparation, T.G.; writing-review and editing, D.S., I.S., Z.B.-M., R.B., A.B., A.M., M.G., S.G., P.A., B.E.; supervision, R.B., A.B., M.G., P.A. All authors have read and agreed to the published version of the manuscript.

Funding: We would like to thank the government of St. Gallen Switzerland and the Principality of Liechtenstein for their financial support and funding of RhySearch. Furthermore, we thank UCM AG and WZW Optic AG for their support in the cleaning and polishing experiments.

Conflicts of Interest: The funding sponsors had no role in the design of the study, in the collection, analyses, or interpretation of data, in the writing of the manuscript, and in the decision to publish the results. The authors declare no conflict of interest.

\section{References}

1. McIntosh, R.B., Jr; Paquin, R.A. Chemical-mechanical polishing of low-scatter optical surfaces. Appl. Opt. 1980, 19, 2329-2331. [CrossRef] [PubMed]

2. Leistner, A.J.; Thwaite, E.G.; Lesha, F.; Bennett, J.M. Polishing study using Teflon and pitch laps to produce flat and supersmooth surfaces. Appl. Opt. 1992, 31, 1472-1482. [CrossRef] [PubMed]

3. Rupp, W.J. Conventional Optical Polishing Techniques. Opt. Acta Int. J. Opt. 1971, 18, 1-16. [CrossRef]

4. Cumbo, M.J.; Fairhurst, D.; Jacobs, S.D.; Puchebner, B.E. Slurry particle size evolution during the polishing of optical glass. Appl. Opt. 1995, 34, 3743-3755. [CrossRef] [PubMed]

5. Krol, H.; Gallais, L.; Grèzes-Besset, C.; Natoli, J.-Y.; Commandré, M. Investigation of nanoprecursors threshold distribution in laser-damage testing. Opt. Commun. 2005, 256, 184-189. [CrossRef] 
6. Pereira, A.; Coutard, J.-G.; Becker, S.; Tovena, I.; Bouchut, P.; Ravel, G. Impact of Organic Contamination on $1064 \mathrm{~nm}$. In Proceedings of the Boulder Damage Symposium XXXVIII: Annual Symposium on Optical Materials for High Power Lasers, Boulder, CO, USA, 25-27 September 2006; Volume 6403.

7. Baxamusa, S.; Miller, P.E.; Wong, L.; Steele, R.; Shen, N.; Bude, J. Mitigation of organic laser damage precursors from chemical processing of fused silica. Opt. Express 2014, 22, 29568-29577. [CrossRef] [PubMed]

8. Gibbs, W.E.K.; McLachlan, A.D. Ultrasonic Cleaning of Optical Surfaces. In Symposium on Laser-Induced Damage in Optical Materials, Boulder, Colorado, USA, 1975; Glass, A.J., Guenther, A.H., Eds.; National Bureau of Standards: Boulder, CO, USA, 1976; NBS Special Publications 435.

9. Krol, H.; Gallais, L.; Commandré, M.; Grèzes-Besset, C.; Torricini, D.; Lagier, G. Influence of polishing and cleaning on the laser-induced damage threshold of substrates and coatings at $1064 \mathrm{~nm}$. Opt. Eng. 2007, 46, 023402-1-023402-5. [CrossRef]

10. Bennett, J.M. How to clean Surfaces. In Proceedings of the XXXV Annual Symposium on Optical Materials for High Power Lasers: Boulder Damage Symposium, Boulder, CO, USA, 22-24 September 2003; Volume 5273.

11. Dijon, J.; Garrec, P.; Kaiser, N.; Schallenberg, U.B. Influence of substrate cleaning on LIDT of $355 \mathrm{~nm}$ HR coatings. In Proceedings of the Laser-Induced Damage in Optical Materials: 1996, Boulder, CO, USA, 7-9 October 1996; Volume 2966.

12. Gu, Z.; Liang, P.; Zhang, W. Influence of glass surface layers on laser-induced damage threshold. In Proceedings of the Boulder Damage, Boulder, CO, USA, 1-3 October 2001; Volume 4679.

13. Field, E.; Bellum, J.; Kletecka, D. Impact of different cleaning processes on the laser damage threshold of antireflection coatings for Z-Backlighter optics at Sandia National Laboratories. Opt. Eng. 2014, 53, 122516-1-122516-8. [CrossRef]

14. Ye, H.; Li, Y.; Yuan, Z.; Wang, J.; Yang, W.; Xu, Q. Laser induced damage characteristics of fused silica optics treated by wet chemical processes. Appl. Surf. Sci. 2015, 357, 498-505. [CrossRef]

15. Shao, J. Laser-Induced Damage in Optical Materials, 1st ed.; Ristau, D., Ed.; CRC Press: Boca Raton, FL, USA, 2014; Chapter 6, pp. 167-169.

16. Jensen, L.; Mrohs, M.; Gyamfi, M.; Mädebach, H.; Ristau, D. Higher certainty of the laser-induced damage threshold test with a redistributing data treatment. Rev. Sci. Instrum. 2015, 86, 103106-1-103106-6. [CrossRef] [PubMed]

17. Karimi, P. Non Destructive Nanoparticle Removal from Sub-micron Structures using Megasonic Cleaning. PhD Thesis, Doctor of Philosophy in the field of Mechanical Engineering Northeastern University, Boston, MA, USA, October 2009.

18. Modutek. Available online: https://modutek.wordpress.com/2019/07/15/how-quick-dump-rinsers-improvesilicon-wet-etching-results/ (accessed on 27 November 2020).

Publisher's Note: MDPI stays neutral with regard to jurisdictional claims in published maps and institutional affiliations.

(C) 2020 by the authors. Licensee MDPI, Basel, Switzerland. This article is an open access article distributed under the terms and conditions of the Creative Commons Attribution (CC BY) license (http://creativecommons.org/licenses/by/4.0/). 